\title{
Rehospitalization with surgical site infections after cardiac surgery
}

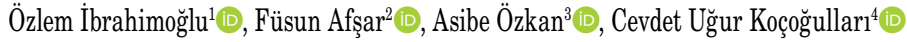 \\ ${ }^{1}$ Department of Nursing, Bilecik Seyh Edebali University School of Health, Bilecik, Turkey \\ 2Department of Nursing, Sultan Abdulhamid Han Training and Research Hospital, Istanbul, Turkey \\ ${ }^{3}$ Department of Nursing, Dr. Siyami Ersek Thoracic and Cardiovascular Surgery Training and Research Hospital, Istanbul, Turkey \\ ${ }^{4}$ Department of Cardiovascular Surgery, Dr. Siyami Ersek Thoracic and Cardiovascular Surgery Training and Research Hospital, Istanbul, Turkey
}

Received: July 23, 2018 Accepted: August 29, 2018 Published online: April 24, 2019

\section{ABSTRACT}

Objectives: This study aims to investigate rehospitalization rates in patients with surgical site infections (SSIs) after cardiac surgery.

Patients and methods: This cross-sectional study included a total of 153 patients $(121$ males, 32 females; mean age $58.7 \pm 10.9$ years; range, 18 to 80 years) who underwent open heart surgery in our cardiovascular surgery clinic and readmitted with SSI within 30 days after surgery between September 2014 and December 2014. Risk factors which were related to the patient, surgery, and hospital stay were evaluated.

Results: Of the patients, $73.8 \%$ had coronary artery bypass grafting (CABG). A total of 22 patients (14.4\%) were readmitted to hospital after discharge with SSI. Half of them had saphenous infections (superficial infection $n=8$, deep infection $n=3$ ), while the other half had sternal infections (superficial infection $n=7$, deep infection $n=4$ ). Nine of these patients were rehospitalized. The mean length of hospital stay was 14.2 \pm 3.8 (range, 10 to 20 ) days. The risk factors for SSI development included patient, surgery, and hospitalization and hospital setting.

Conclusion: Our study results show that several risk factors may play a role in the development of SSIs and rehospitalization. Therefore, it is recommended that nurses consider that SSI is certainly a major complication after cardiac surgery and the risks should be minimized during procedure and after discharge.

Keywords: Cardiac surgery, rehospitalization, surgical site infection.

Surgical site infections (SSIs) are serious perioperative complications which accounts for about $2 \%$ of surgical procedures and they may have a devastating impact on the course of treatment. ${ }^{[1-3]}$ These infections are also associated with increased treatment intensity and prolonged length of hospital stay, and higher cumulative healthcare costs and substantial morbidity and mortality rates. ${ }^{[3]}$

Infectious complications after cardiac surgery, which occur in 5 to $21 \%$ of cases, are well-known and difficult-to-treat problems which increase patients' suffer, healthcare cost, and postoperative mortality rates by more than five times with prolonged recovery. ${ }^{[4,5]}$

There are three types of SSI defined by the Centers for Disease Control and Prevention (CDC). According to the $\mathrm{CDC}$, SSIs are classified as either incisional or organ/space with incisional SSIs being further subcategorized as superficial (involving only skin and subcutaneous tissue) and versus deep SSIs (involving underlying soft tissue). ${ }^{[3,6]}$
In cardiac surgery, the most common sites of infections are the respiratory tract (45.7 to $57.8 \%$ ), surgical site $(27.7 \%)$, and catheters or devices (20.5 to 25.2\%). ${ }^{[5]}$ Surgical site infections include superficial infections of the postoperative scar and deep wound infections. ${ }^{[7]}$ Superficial sternal wound infections complicate 0.5 to $8 \%$ of cardiac surgery cases and involve the skin, subcutaneous tissue, and pectoralis fascia. Deep sternal wound infections involve the sternal bone, substernal space, and mediastinum, but are less common than superficial sternal wound infections with an incidence ranging between 0.4 and $2 \% .^{[5]}$

Corresponding author: Özlem İbrahimoğlu. Bilecik Șeyh Edebali Üniversitesi, Sağllk Yüksekokulu, Hemşirelik Anabilim Dalı, 11210 Bilecik, Turkey.

Tel: +90 228 - 2142173 e-mail: oogutlu@gmail.com

Citation:

İbrahimoğlu 0̈, Afşar F, Özkan A, Koçoğulları CU. Rehospitalization with surgical site infections after cardiac surgery. Cardiovasc Surg Int 20189;6(1):12-20. 
The contamination of the operative site may be due to the patient's endogenous flora or to the surgical team's or operating room's exogenous flora and is often perioperative. In addition, some factors promote the occurrence of SSI from this contamination such as tissue necrosis, hematoma, foreign body of a prosthesis or of an implant, and poor vascularization. ${ }^{[7]}$

Patients may be contaminated before, during, or after surgery, and any reoperation exposes to the risk of SSIs. The risk factors are related to three factors including patient, surgery, and hospitalization. Risk factors related to the patient are age, sex, obesity, diabetes mellitus (DM), respiratory insufficiency, stroke, heart failure, atrial fibrillation, smoking, peripheral vascular disease, renal failure, cardiogenic shock, and myocardial infarction (MI). Risk factors related to surgery are type of emergency, type of surgery, operation time, prolonged perfusion time, postoperative hemorrhage, early surgical revision for bleeding, steroids, prolonged mechanical ventilation, use of intra-aortic counterpulsation devices, blood transfusion, and reoperative heart surgery (redo) surgery. Risk factors related to hospitalization and hospital setting are duration of preoperative stay and patient preparation. ${ }^{[2,5,7]}$ These predictors may result in development of SSIs after cardiac surgery through three common physiological pathways: decreased collagen synthesis, vasoconstriction, and increased immunosuppression. ${ }^{[3]}$

In the literature, several studies have been undertaken to identify high-risk patients for infectious complications in an attempt to modify risk factors. Early recognition of an infection is of utmost importance for optimal treatment and management of the patient. ${ }^{[4]}$

In the present study, we aimed to investigate rehospitalization rates in patients with SSIs after cardiac surgery.

\section{PATIENTS AND METHODS}

This cross-sectional study was conducted at a university-affiliated hospital, located in Istanbul, Turkey between September 2014 and December 2014. A total of 153 patients (121 males, 32 females; mean age $58.7 \pm 10.9$ years; range, 18 to 80 years) who underwent open heart surgery in our cardiovascular surgery clinic and readmitted with SSI within 30 days after surgery were included. Inclusion criteria were as follows: having open heart surgery via median sternotomy under standard cardiopulmonary bypass (CPB) including coronary artery bypass grafting (CABG), valve repair, atrial/ventricular septal defect (ASD/VSD) repair surgery, aneurysm surgery, atrial mass excision, and redo surgery. Exclusion criteria were as follows: having heart transplantation and pacemaker implantation. A written informed consent was obtained from each patient. The study protocol was approved by the Dr. Siyami Ersek Thoracic and Cardiovascular Surgery Training and Research Hospital Ethics Committee. The study was conducted in accordance with the principles of the Declaration of Helsinki.

The data were obtained with the Structured Patient Information Form which included demographic and perioperative data. The standard anesthesiology management, myocardial protection techniques, and ventilator-weaning process were performed. The perfusion temperature was allowed to decrease to $28^{\circ} \mathrm{C}$ during $\mathrm{CPB}$ and standard cold potassium cardioplegia solution was used for all patients. The patients were transferred directly from the operating room to the cardiovascular intensive care unit (CVICU). All patients were mechanically ventilated on synchronized intermittent mandatory ventilation (SIMV) with a tidal volume of 10 to $12 \mathrm{~mL} / \mathrm{kg}$, a respiratory rate of 10 to $12 / \mathrm{min}$, and a fraction of inspired oxygen rate of $100 \%$. The nurses evaluated the hemodynamic, neurological, and respiratory state of the patients. Once the patients were fully awake, the nurse made the decision to extubate the patient, if they met the extubation criteria. Education and training were also given to all patients before operation and before discharge about what they should pay attention. All patients were followed for 30 days after surgery for SSI development.

The preoperative variables were defined as the age, sex, body mass index (BMI), documented DM, renal failure, heart failure, respiratory insufficiency (chronic obstructive pulmonary disease [COPD]), peripheral vascular disease, cardiogenic shock, MI, and smoking. The intraoperative variables included type of emergency, type of surgery, duration of aortic cross-clamp and $\mathrm{CPB}$, total operation time, blood transplantation, use of intra-aortic counterpulsation devices (i.e., intra-aortic balloon pump [IABP]), and redo rates. Other variables including the surgeon, anesthesiology technique, cardioplegia solution, and hypothermia were stable and they were not tested.

\section{Statistical analysis}

Statistical analysis was performed using the SPSS version 15.0 (SPSS Inc., Chicago, IL, USA). Descriptive 
data were expressed in mean \pm standard deviation (SD) or number and frequency. The chi-square test, Fisher's exact test, Student's t-test, and Mann-Whitney U test were used to evaluate rehospitalization as the dependent variable and demographic and perioperative variables as the independent variables. A $p$ value of $\mathrm{p}<0.05$ was considered statistically significant.

\section{RESULTS}

Of the patients, the mean BMI was $28.0 \pm 4.2 \mathrm{~kg} / \mathrm{m}^{2}$. A total of $24.8 \%$ patients were smokers. The majority of the patients underwent CABG $(\mathrm{n}=113,73.8 \%)$, followed by valve surgery $(\mathrm{n}=21,13.7 \%)$, combined
CABG + valve surgery $(\mathrm{n}=9,5.8 \%), \mathrm{ASD} / \mathrm{VSD}$ repair surgery $(n=2,1.3 \%)$, aneurysm surgery $(n=2,1.3 \%)$, atrial mass excision $(\mathrm{n}=2,1.3 \%)$, and redo surgery $(n=2,1.3 \%)$. A total of 11 patients (7.2\%) underwent an emergent surgical procedure. Baseline demographic and clinical characteristics of the patients are presented in Table 1.

A total of 22 patients (14.4\%) readmitted with SSI. Eleven (50\%) of them had saphenous infections (superficial infection $n=8$, deep infection $n=3$ ), while the remaining patients had sternal infections (superficial infection $n=7$, deep infection $n=4$ ). Culture examples were obtained from 14 of these patients and

\begin{tabular}{|c|c|c|c|c|c|c|c|c|c|c|}
\hline & & Demog & phic and $p$ & $\begin{array}{l}\text { Table } \\
\text { opera }\end{array}$ & ve varis & les of patien & & & & \\
\hline & & spitaliz & ion $(n=22)$ & Not $r$ & hospitali & ation $(\mathrm{n}=131)$ & & Total & $=153)$ & \\
\hline & $\mathrm{n}$ & $\%$ & Mean \pm SD & $\mathrm{n}$ & $\%$ & Mean \pm SD & $\mathrm{n}$ & $\%$ & Mean \pm SD & $p$ \\
\hline Age (year) & & & $58.5 \pm 14.7$ & & & $59.9 \pm 10.2$ & & & $59.6 \pm 10.9$ & 0.578 \\
\hline Sex & & & & & & & & & & 0.408 \\
\hline Female & 6 & 27.3 & & 26 & 19.8 & & & 20.9 & & \\
\hline Male & 16 & 72.7 & & 105 & 80.2 & & & 79.1 & & \\
\hline BMI & & & $29.0 \pm 4.2$ & & & $27.8 \pm 4.2$ & & & $27.9 \pm 4.2$ & 0.209 \\
\hline Life & & & & & & & & & & 0.331 \\
\hline Alone & 2 & 9.1 & & 7 & 5.3 & & 9 & 5.9 & & \\
\hline With family & 20 & 90.1 & & 124 & 94.6 & & 144 & 94.1 & & \\
\hline Smoking & & & & & & & & & & 0.002 \\
\hline Yes & 12 & 54.5 & & 26 & 19.8 & & 38 & 24.8 & & \\
\hline No & 10 & 45.5 & & 105 & 80.2 & & 115 & 75.2 & & \\
\hline Diabetes mellitus & & & & & & & & & & 0.374 \\
\hline Yes & 9 & 40.9 & & 41 & 31.3 & & 50 & 32.7 & & \\
\hline No & 13 & 59.1 & & 90 & 68.7 & & 103 & 67.3 & & \\
\hline Renal failure & & & & & & & & & & 0.003 \\
\hline Yes & 3 & 13.6 & & 0 & 0.0 & & 3 & 2.0 & & \\
\hline No & 19 & 86.4 & & 131 & 100.0 & & 150 & 98.0 & & \\
\hline Heart failure & & & & & & & & & & 0.217 \\
\hline Yes & 0 & 0.0 & & 13 & 9.9 & & 13 & 8.5 & & \\
\hline No & 22 & 100.0 & & 118 & 90.1 & & 140 & 91.5 & & \\
\hline Peripheral vascular disease & & & & & & & & & & 0.374 \\
\hline Yes & 1 & 4.5 & & 2 & 1.5 & & 3 & 2.0 & & \\
\hline No & 21 & 95.5 & & 129 & 98.5 & & 150 & 98.0 & & \\
\hline COPD & & & & & & & & & & 0.587 \\
\hline Yes & 2 & 9.1 & & 11 & 8.4 & & 13 & 8.5 & & \\
\hline No & 20 & 90.9 & & 120 & 91.6 & & 140 & 91.5 & & \\
\hline Cardiogenic shock & & & & & & & & & & 0.268 \\
\hline Yes & 1 & 4.5 & & 1 & 0.8 & & 2 & 1.3 & & \\
\hline No & 21 & 95.5 & & 130 & 99.2 & & 151 & 98.7 & & \\
\hline Preoperative myocardial infarction & & & & & & & & & & 0.691 \\
\hline Yes & 8 & 36.4 & & 42 & 32.1 & & 50 & 32.7 & & \\
\hline No & 14 & 63.6 & & 89 & 67.9 & & 103 & 67.3 & & \\
\hline
\end{tabular}


were found to be positive in eight. In total, 5.9\% ( $\mathrm{n}=9)$ and $41 \%(n=8)$ of SSI patients were rehospitalized. The mean length of hospital stay in these patients was 14.2 \pm 3.8 (range, 10 to 20 ) days (Figure 1 ).

Of a total of 22 patients who were rehospitalized, the majority was male $(72.7 \%)$ with a mean age of $58.5 \pm 14.7$ years and a mean BMI of $29.0 \pm 4.2 \mathrm{~kg} / \mathrm{m}^{2}$. However, there was no statistically significant difference between the patients with and without rehospitalization.

In terms of patient-related risk factors, there was no statistically significant difference between the patients with rehospitalization in terms of the living alone or with their family, DM, heart failure, peripheral vascular disease, COPD, cardiogenic shock, and MI before surgery ( $p>0.05)$. However, there was a statistically significant difference between the patients with rehospitalization in terms of smoking and having renal failure $(\mathrm{p}<0.05)$ and a higher number of these patients were readmitted to hospital with SSI (Table 1).

In terms of surgery risk factors, there was a statistically significant difference only between the patients with rehospitalization with SSI in terms of the use of IABP $(\mathrm{p}<0.05)$. On the other hand, there was no statistically significant difference between the patients with rehospitalization with SSI in terms of the type of emergency, type of surgery, $\mathrm{CPB}$, aortic crossclamp time, operation time, and blood transfusion. In addition, there was no statistically significant difference between the patients with rehospitalization with SSI in terms of having normal or higher blood glucose level (Table 2). In terms of hospitalization and hospital setting, all patients received the same preparation to surgery and were hospitalized in the same hospital the day before surgery. After surgery,

\begin{tabular}{|c|c|c|c|c|c|c|c|c|c|c|}
\hline & & Intra & and posto & $\begin{array}{l}\text { ble } 2 \\
\text { rative }\end{array}$ & ata of & atients & & & & \\
\hline & $\operatorname{Re}$ & ospitaliz & $\operatorname{tion}(\mathrm{n}=22)$ & Not re & ospital & ation $(n=131)$ & & Total & $\mathrm{n}=60)$ & \\
\hline & $\mathrm{n}$ & $\%$ & Mean \pm SD & $\mathrm{n}$ & $\%$ & Mean \pm SD & $\mathrm{n}$ & $\%$ & Mean \pm SD & $p$ \\
\hline Type of surgery & & & & & & & & & & 0.367 \\
\hline Elective & 22 & 100.0 & & 120 & 91.6 & & 142 & 92.8 & & \\
\hline Emergency & 0 & 0.0 & & 11 & 8.4 & & 11 & 7.2 & & \\
\hline Cardiopulmonary bypass time (min) & & & $117.4 \pm 42.7$ & & & $112.0 \pm 45.7$ & & & $112.8 \pm 45.2$ & 0.459 \\
\hline Aortic cross-clamping time (min) & & & $78.2 \pm 38.1$ & & & $74.8 \pm 35.2$ & & & $75.3 \pm 35.5$ & 0.706 \\
\hline Operation time $(\mathrm{h})$ & & & $4.7 \pm 0.9$ & & & $4.5 \pm 1.0$ & & & $4.5 \pm 1.0$ & 0.488 \\
\hline Stay in CVICU (h) & & & $32.1 \pm 18.9$ & & & $36.8 \pm 25.5$ & & & $36.1 \pm 24.7$ & 0.224 \\
\hline IABP used & & & & & & & & & & 0.039 \\
\hline Yes & 3 & 13.6 & & 3 & 2.3 & & 6 & 3.9 & & \\
\hline No & 19 & 86.4 & & 128 & 97.7 & & 147 & 96.1 & & \\
\hline Blood Tx in CVICU & & & & & & & & & & 0.785 \\
\hline Yes & 18 & 81.8 & & 101 & 77.1 & & 119 & 77.8 & & \\
\hline No & 4 & 18.2 & & 30 & 22.9 & & 34 & 22.2 & & \\
\hline Blood $\mathrm{Tx}$ in Clinic & & & & & & & & & & 1.000 \\
\hline Yes & 3 & 13.6 & & 18 & 13.7 & & 21 & 13.7 & & \\
\hline No & 19 & 86.4 & & 113 & 86.3 & & 132 & 86.3 & & \\
\hline Blood glucose regulation in CVICU & & & & & & & & & & 0.532 \\
\hline Normal & 9 & 40.9 & & 63 & 48.1 & & 72 & 47.1 & & \\
\hline High & 13 & 59.1 & & 68 & 51.9 & & 81 & 52.9 & & \\
\hline Blood glucose regulation after & & & & & & & & & & 0.976 \\
\hline CVICU & 12 & 54.5 & & 71 & 54.2 & & 83 & 54.2 & & \\
\hline Normal & 10 & 45.5 & & 60 & 45.8 & & 70 & 45.8 & & \\
\hline 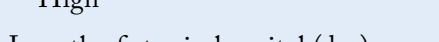 & & & & & & & & & & \\
\hline Length of stay in hospital (day) & & & $8.9 \pm 4.1$ & & & $7.9 \pm 3.2$ & & & $8.0 \pm 3.3$ & 0.081 \\
\hline
\end{tabular}




\begin{tabular}{|c|c|c|c|c|c|c|c|}
\hline \multicolumn{8}{|c|}{$\begin{array}{c}\text { Table } 3 \\
\text { Patient data after discharge }\end{array}$} \\
\hline & \multicolumn{2}{|c|}{ Rehospitalization $(\mathrm{n}=22)$} & \multicolumn{2}{|c|}{ Not rehospitalization $(n=131)$} & \multicolumn{2}{|c|}{ Total $(n=60)$} & \multirow[b]{2}{*}{$p$} \\
\hline & $\mathrm{n}$ & $\%$ & $\mathrm{n}$ & $\%$ & $\mathrm{n}$ & $\%$ & \\
\hline Wound appearance before discharge & & & & & & & 0.540 \\
\hline Clean & 21 & 95.5 & 128 & 97.7 & 149 & 97.4 & \\
\hline Swollen & 1 & 4.5 & 3 & 2.3 & 4 & 2.6 & \\
\hline Bath after discharge & & & & & & & 0.020 \\
\hline Yes & 20 & 90.9 & 131 & 100.0 & 151 & 98.7 & \\
\hline No & 2 & 9.1 & 0 & 0.0 & 2 & 1.3 & \\
\hline Bath frequency & & & & & & & 0.110 \\
\hline Everyday & 1 & 4.5 & 0 & 0.0 & 1 & 0.7 & \\
\hline Every other day & 6 & 27.3 & 39 & 29.8 & 45 & 29.4 & \\
\hline Once a week & 14 & 63.6 & 87 & 66.4 & 101 & 66.0 & \\
\hline Two in a week & 1 & 4.5 & 5 & 3.8 & 6 & 3.9 & \\
\hline
\end{tabular}

the mean length of stay in hospital was $8.9 \pm 4.1$ days in rehospitalization patients and $7.9 \pm 3.2$ days in nonSSI patients. There was no statistically significant difference between the patients with rehospitalization with SSI in terms of the length of stay in hospital (p>0.05) (Table 2).

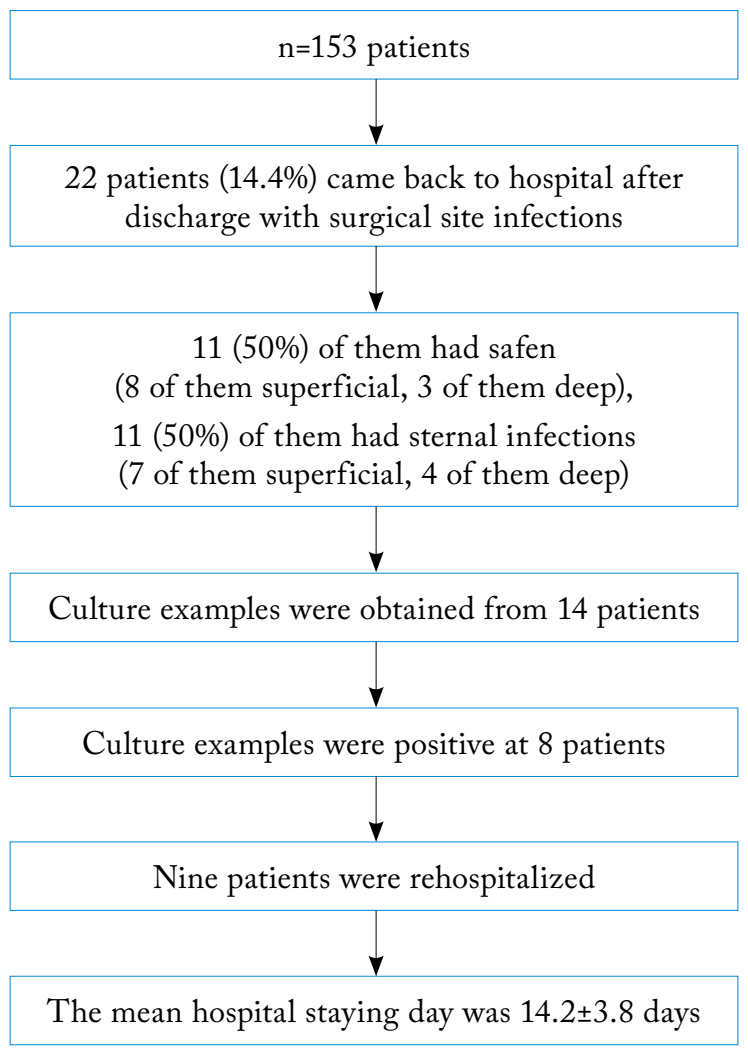

Figure 1. Flow chart of rehospitalization of patients after cardiac surgery.
On the other hand, we found a statistically significant difference between the patients with rehospitalization with SSI in terms of having bath after discharge $(p<0.05)$ and having bath was associated with decreased SSI rates (Table 3).

\section{DISCUSSION}

Surgical site infections have a negative effect on the postoperative recovery period. They are associated with increased treatment intensity, prolong lenght of stay, higher costs, morbidity, and mortality. ${ }^{[1,3,8-10]}$ Major postoperative infections including bloodstream infections and SSIs occur in up to $5 \%$ of patients after cardiac surgery. ${ }^{[10,11]}$

The reported incidence of infectious complications after cardiac surgery has ranged between 5 to $21 \%$ of cases. ${ }^{[12]}$ While superficial sternal wound infections include skin, subcutaneous tissue and pectoralis fascia, deep sternal wound infections involve the sternal bone, substernal space and the mediastinum, and occur in 0.5 to $8 \%$ and 0.4 to $2 \%$ respectively. ${ }^{[5]}$ In this study, the SSI rates were found to be similar with the literature.

Hannan et al. ${ }^{[13]}$ and Li et al. ${ }^{[14]}$ reported an all-cause readmission rate of 16.5 and $13.2 \%$, respectively within 30 days of CABG. Both aforementioned authors concluded that postoperative infection was the most common reason for rehospitalization, consistent with our study findings.

The mortality rate of patients who develop SSI after cardiac surgery is significantly higher than those without SSI, ranging between 22 and $40 \% \cdot{ }^{[3]}$ In our study, there were no infection-related mortality. 
In recent years, there are many attempts to identify predictors for the development of SSI after cardiac surgery in the field of surgery. ${ }^{[3]}$ The management of SSI is complex and prevention according to the risk factor modification offers the most effective intervention. A host of independent risk factors have been identified for SSIs. ${ }^{[5]}$ These predictors have been also examined in terms of patient, surgery, and hospitalization.

The patient-related predictors are age ( $>85$ years), sex, obesity $\left(\mathrm{BMI}>30 \mathrm{~kg} / \mathrm{m}^{2}\right)$, concomitant diseases (i.e., COPD, respiratory failure, renal failure and hemodialysis, DM, cardiogenic shock, history of MI, and aortic calcification), the use immunosuppressive agents, and smoking. Risk factors for surgery are type of surgery (combined valve $+\mathrm{CABG}$ and aortic procedures), reexploration (reopening) for bleeding, blood transfusions, CPB time, and using IABP. Risk factors for hospitalization are preoperative length of stay in hospital more than three days, and preparation of the patient for surgery. ${ }^{[5,15,16]}$ In this study, the age, sex, BMI, DM, heart failure, peripheral vascular disease, COPD, cardiogenic shock, and preoperative MI did not show a significant correlation with SSIs. However, smoking and renal failure were significantly associated with SSI development.

Several studies demonstrated that age, female sex, high preoperative serum glucose levels ( $>200 \mathrm{mg} / \mathrm{dL}$ ), DM, obesity, and smoking were statistically significantly correlated with SSI development. ${ }^{[11,17,18]}$ Bhatia et al. ${ }^{[17]}$ reported that, in patients over the age of 66 years, the changes of developing wound infections were twice as high as in patients aged between 21 and 50 years.

On the other hand, there are conflicting reports on sex as a risk factor for SSI development. Some authors have reported an increased risk, while some others have shown a decreased risk in males. ${ }^{[19]}$ There are also reports showing no significant correlation between sex and SSI development. Rogers et al. ${ }^{[20]}$ reported that women were more likely to receive allogeneic red blood cells or platelets than men. The authors found that patients who received allogeneic blood were 4.4 times more likely to develop an infection than those who did not and women had a greater risk of infection.

Kanafani et al. ${ }^{[21]}$ and Fowler et al. ${ }^{[11]}$ reported that a BMI of $>40 \mathrm{~kg} / \mathrm{m}^{2}$, chronic renal failure with hemodialysis, and chronic lung disease had a higher risk of developing major infections after cardiac surgery. In addition, Rahmanian et al. ${ }^{[22]}$ reported that a BMI value of exceeding $30 \mathrm{~kg} / \mathrm{m}^{2}$ and diabetes were the main predictors for SSI development.

Furthermore, several studies have shown that obesity has a weak correlation with SSI and having sternotomy. ${ }^{[23]}$ The possible reason for obesity being a risk factor include ineffective dose of prophylactic antibiotics, difficulty in proper skin preparation, adipose tissue providing a good substrate for infection and difficulties in vascular graft harvesting. ${ }^{[17]}$

Diabetes, particularly uncontrolled diabetes, is a significant independent risk factor for the development of SSI in perioperative cardiac surgical patients. ${ }^{[3,11,16,17,24]}$ High perioperative blood glucose concentrations have been identified as a risk factor for SSI after cardiothoracic surgery. ${ }^{[15,21,25]}$ In patients with diabetes, postoperative hyperglycemia has been also associated with adverse outcomes such as death, MI, stroke, and septic complications before hospital discharge. ${ }^{[3,21,25-27]}$ Maintaining a serum glucose of $<180 \mathrm{mg} / \mathrm{dL}$ with continuous insulin infusions in patients with and without DM reduces morbidity and mortality, lowers the incidence of sternal wound infections, shortens hospital length of stay, and improves long-term survival. ${ }^{[28]}$ Poor glycemic control prior to surgery, however, contributes to poor diabetes control after hospital discharge and increases the incidence of complications, such as poor wound healing and higher rates of SSI, and rehospitalization and increased mortality, eventually. ${ }^{[29,30]}$ It is likely that the benefits of glucose control extend to cardiac surgical patients, as most of the large-scale glucose control studies included cardiothoracic surgery patients and as poor glucose control is associated with a higher risk of SSI. ${ }^{[5,31,32]}$

In this study, CPB time, aortic cross-clamp time, operation time, length of stay in the ICU, blood transfusion, blood glucose regulation, and type of surgery did not show a significant correlation with the SSI development. However, the use of IABP was found to be significantly associated with the SSI development.

In our study, the mean duration of surgery was $4.5 \pm 1.0$ (min: 2-max: 8) hours. Duration of surgery may be also a risk factor. Operations lasting for more than two hours are known to be associated with increased infection rates. ${ }^{[17]}$ Fowler et al. ${ }^{[11]}$ reported that infections were associated with perfusion time (200 to $300 \mathrm{~min}$ ), placement of IABP, and the presence of three or more distal anastomoses. 
In recent studies, blood transfusion has been identified as an independent risk factor. Blood transfusion is associated with impaired immunocompetence. ${ }^{[17]}$ Although transfusion may be necessary to prevent or treat tissue hypoxia, the immunomodulatory effects of allogeneic blood transfusion have been recognized for decades. Transfusion-related immunomodulation has been also shown to result in an increased risk of nosocomial infections and mortality in many patient cohorts. ${ }^{[3]}$ Rogers et al. ${ }^{[20]}$ reported that patients who received allogenic blood transfusion were four times more likely to develop infection after cardiac surgery. However, in our study, there was no statistically significant correlation between the use of blood transfusion and rehospitalization.

Postoperative SSI increased the length of hospital stay and cost in proportion to the severity of infection. The cost increased by $3.8 \%, 14.7 \%$, and $29.4 \%$ in mild, moderate, and severe infections, respectively. ${ }^{[17]}$ In a study, the length of hospital stay was found to be 5.9 and 15 days, respectively. ${ }^{[17]}$ Fowler et al. ${ }^{[11]}$ showed that $47 \%$ of cardiac surgery patients with SSI required more than 14 days in the hospital. In another study, the presence of SSI prolonged the length of stay by about 9.7 (range, 6 to 14) days. ${ }^{[3]}$ This increase in the length of stay is also consistent with our study findings.

Skin preparation for surgery is one of the key elements to prevent postoperative infections. Investigating skin preparation modalities, such as hair removal and preoperative antiseptic showering, would build further evidence for best nursing practice and help nurse managers to develop and implement a protocol for appropriate preoperative skin preparation. ${ }^{[2,3]}$

Although postoperative wound care and dressing is well-investigated in the literature, there is a limited number of data regarding the timing for the first dressing as the predictor for SSIs. Timing of the first postoperative dressing affects the inflammatory phase of wound healing. ${ }^{[33]}$ The duration of the inflammatory phase of wound healing is about two to three days. Investigating whether to cover the wound for two to three days affects the wound infection rate would be helpful to develop and implement a protocol for the wound care postoperatively. ${ }^{[3]}$

In their study, Dal et al. ${ }^{[34]}$ reported that, after discharge, $24.5 \%$ of patients experienced a problem related to caring at home, $60.4 \%$ had surgery wound infections, and $63.5 \%$ patients were readmitted to hospital. Good discharge planning and home-based care services would improve patient recovery following surgery and prevent complications. Postoperative bathing and showering may also remove the dead skin cells, dirt, microorganisms, and sweat that have collected around the wound edges. It may also reduce contamination of the surgical site, help to prevent infection, and promote wound healing. ${ }^{[35,36]}$ However, in a study, Toon et al. ${ }^{[36]}$ reported no statistically significant difference in the rate of SSI development between the patients having early versus late postoperative bathing. In another study, $\mathrm{Ucar}^{[37]}$ also reported that the postoperative rate of infectious complications was similar in patients having early versus late postoperative bathing.

This study has some limitations. First, all of the patients studied were from a single academic medical center, and our results may not represent patients developing SSI in other institutions. Second, this study does not take into account the socioeconomic status that may lead to infection development while addressing some factors affecting the development of infection.

In conclusion, infectious complications can be reduced with many simple measures, starting with risk factor modification at the first anesthetic preoperative screening visit thorough to postoperative risk factor vigilance in the intensive care unit and after discharge. Nurse-led reminder systems, care bundles, admission order sets, and discharge protocols appear to be particularly effective at meeting the quality targets in the management of Surgical site infections. ${ }^{[3,38]}$ Of note, Surgical site infections are certainly major complications of cardiovascular surgery. It should be, therefore, kept in mind that risk factors should be minimized during the procedure to employ more effective preventive measures for postoperative wound infections.

\section{Declaration of conflicting interests}

The authors declared no conflicts of interest with respect to the authorship and/or publication of this article.

\section{Funding}

The authors received no financial support for the research and/or authorship of this article.

\section{REFERENCES}

1. de Lissovoy G, Fraeman K, Hutchins V, Murphy D, Song D, Vaughn BB. Surgical site infection: incidence and impact 
on hospital utilization and treatment costs. Am J Infect Control 2009;37:387-97.

2. Hanedan MO, Ünal EU, Aksöyek A, Başar V, Tak S, Tütün U, et al. Comparison of two different skin preparation strategies for open cardiac surgery. J Infect Dev Ctries 2014;8:885-90.

3. Musallam E. The predictors of surgical site infection post cardiac surgery: a systematic review. J Vasc Nurs 2014;32:105-18.

4. Tegnell A, Arén C, Ohman L. Wound infections after cardiac surgery--a wound scoring system may improve early detection. Scand Cardiovasc J 2002;36:60-4.

5. Cove ME, Spelman DW, MacLaren G. Infectious complications of cardiac surgery: a clinical review. J Cardiothorac Vasc Anesth 2012;26:1094-100.

6. Mangram AJ, Horan TC, Pearson ML, Silver LC, Jarvis WR. Guideline for Prevention of Surgical Site Infection, 1999. Centers for Disease Control and Prevention (CDC) Hospital Infection Control Practices Advisory Committee. Am J Infect Control 1999;27:97-132.

7. Lepelletier D, Bourigault C, Roussel JC, Lasserre C, Leclère $\mathrm{B}$, Corvec S, et al. Epidemiology and prevention of surgical site infections after cardiac surgery. Med Mal Infect 2013;43:403-9.

8. Coskun D, Aytac J, Aydinli A, Bayer A. Mortality rate, length of stay and extra cost of sternal surgical site infections following coronary artery bypass grafting in a private medical centre in Turkey. J Hosp Infect 2005;60:176-9.

9. Lucet JC. Surgical site infection after cardiac surgery: a simplified surveillance method. Infect Control Hosp Epidemiol 2006;27:1393-6.

10. Chen LF, Arduino JM, Sheng S, Muhlbaier LH, Kanafani $\mathrm{ZA}$, Harris AD, et al. Epidemiology and outcome of major postoperative infections following cardiac surgery: risk factors and impact of pathogen type. Am J Infect Control 2012;40:963-8.

11. Fowler VG Jr, O'Brien SM, Muhlbaier LH, Corey GR, Ferguson TB, Peterson ED. Clinical predictors of major infections after cardiac surgery. Circulation 2005;112:358-65.

12. Michalopoulos A, Geroulanos S, Rosmarakis ES, Falagas ME. Frequency, characteristics, and predictors of microbiologically documented nosocomial infections after cardiac surgery. Eur J Cardiothorac Surg 2006;29:456-60.

13. Hannan EL, Zhong Y, Lahey SJ, Culliford AT, Gold JP, Smith $\mathrm{CR}$, et al. 30-day readmissions after coronary artery bypass graft surgery in New York State. JACC Cardiovasc Interv 2011;4:569-76.

14. Li Z, Armstrong EJ, Parker JP, Danielsen B, Romano PS. Hospital variation in readmission after coronary artery bypass surgery in California. Circ Cardiovasc Qual Outcomes 2012;5:729-37.

15. Garey KW, Kumar N, Dao T, Tam VH, Gentry LO. Risk factors for postoperative chest wound infections due to gram-negative bacteria in cardiac surgery patients. J Chemother 2006;18:402-8.
16. Filsoufi F, Castillo JG, Rahmanian PB, Broumand SR, Silvay G, Carpentier A, et al. Epidemiology of deep sternal wound infection in cardiac surgery. J Cardiothorac Vasc Anesth 2009;23:488-94.

17. Bhatia JY, Pandey K, Rodrigues C, Mehta A, Joshi VR. Postoperative wound infection in patients undergoing coronary artery bypass graft surgery: a prospective study with evaluation of risk factors. Indian J Med Microbiol 2003;21:246-51.

18. Haas JP, Evans AM, Preston KE, Larson EL. Risk factors for surgical site infection after cardiac surgery: the role of endogenous flora. Heart Lung 2005;34:108-14.

19. Borger MA, Rao V, Weisel RD, Ivanov J, Cohen G, Scully HE, et al. Deep sternal wound infection: risk factors and outcomes. Ann Thorac Surg 1998;65:1050-6.

20. Rogers MA, Blumberg N, Heal JM, Hicks GL Jr. Increased risk of infection and mortality in women after cardiac surgery related to allogeneic blood transfusion. J Womens Health (Larchmt) 2007;16:1412-20.

21. Kanafani ZA, Arduino JM, Muhlbaier LH, Kaye KS, Allen $\mathrm{KB}$, Carmeli Y, et al. Incidence of and preoperative risk factors for Staphylococcus aureus bacteremia and chest wound infection after cardiac surgery. Infect Control Hosp Epidemiol 2009;30:242-8.

22. Rahmanian PB, Adams DH, Castillo JG, Chikwe J, Filsoufi F. Tracheostomy is not a risk factor for deep sternal wound infection after cardiac surgery. Ann Thorac Surg. 2007 Dec;84:1984-91.

23. Lilienfeld DE, Vlahov D, Tenney JH, McLaughlin JS. Obesity and diabetes as risk factors for postoperative wound infections after cardiac surgery. Am J Infect Control 1988;16:3-6.

24. Centofanti P, Savia F, La Torre M, Ceresa F, Sansone F, Veglio V, et al. A prospective study of prevalence of 60 -days postoperative wound infections after cardiac surgery. An updated risk factor analysis. J Cardiovasc Surg (Torino) 2007;48:641-6.

25. Lepelletier D, Perron S, Bizouarn P, Caillon J, Drugeon $\mathrm{H}$, Michaud JL, et al. Surgical-site infection after cardiac surgery: incidence, microbiology, and risk factors. Infect Control Hosp Epidemiol 2005;26:466-72.

26. Harrington G, Russo P, Spelman D, Borrell S, Watson K, Barr W, et al. Surgical-site infection rates and risk factor analysis in coronary artery bypass graft surgery. Infect Control Hosp Epidemiol 2004;25:472-6.

27. Gualis J, Flórez S, Tamayo E, Alvarez FJ, Castrodeza J, Castaño M. Risk factors for mediastinitis and endocarditis after cardiac surgery. Asian Cardiovasc Thorac Ann 2009;17:612-6.

28. Lazar HL. How important is glycemic control during coronary artery bypass? Adv Surg 2012;46:219-35.

29. Engoren M, Schwann TA, Habib RH. Elevated hemoglobin Alc is associated with readmission but not complications. Asian Cardiovasc Thorac Ann 2014;22:800-6.

30. Boreland L, Scott-Hudson M, Hetherington K, Frussinetty A, Slyer JT. The effectiveness of tight glycemic control on decreasing surgical site infections and readmission rates in 
adult patients with diabetes undergoing cardiac surgery: A systematic review. Heart Lung 2015;44:430-40.

31. Ridderstolpe L, Gill H, Granfeldt H, Ahlfeldt H, Rutberg H. Superficial and deep sternal wound complications: incidence, risk factors and mortality. Eur J Cardiothorac Surg 2001;20:1168-75.

32. Haley VB, Van Antwerpen C, Tsivitis M, Doughty D, Gase KA, Hazamy $\mathrm{P}$, et al. Risk factors for coronary artery bypass graft chest surgical site infections in New York State, 2008. Am J Infect Control 2012;40:22-8.

33. Harrop JS, Styliaras JC, Ooi YC, Radcliff KE, Vaccaro AR, $\mathrm{Wu}$ C. Contributing factors to surgical site infections. J Am Acad Orthop Surg 2012;20:94-101.

34. Dal Ü, Bulut H, Güler Demir S. Cerrahi girişim sonrası hastaların evde yaşadıkları sorunlar. Bakırköy Tıp Dergisi 2012;8:34-40.
35. Dayton P, Feilmeier M, Sedberry S. Does postoperative showering or bathing of a surgical site increase the incidence of infection? A systematic review of the literature. J Foot Ankle Surg 2013;52:612-4.

36. Toon CD, Sinha S, Davidson BR, Gurusamy KS. Early versus delayed post-operative bathing or showering to prevent wound complications. Cochrane Database Syst Rev 2013;10:CD010075.

37. Uçar MG. Does bathing of a surgical site increase the incidance of infection after cesarean section? Türkiye Klinikleri Jinekoloji Obstetrik 2016;26:98-102.

38. National Nosocomial Infections Surveillance System. National Nosocomial Infections Surveillance (NNIS) System Report, data summary from January 1992 through June 2004, issued October 2004. Am J Infect Control 2004;32:470-85. 